\title{
Expression of skeletal muscle sarcoplasmic reticulum calcium-ATPase is reduced in rats with postinfarction heart failure
}

\author{
A Simonini, K Chang, P Yue, C S Long, B M Massie
}

\begin{abstract}
Objective-To determine whether heart failure in rats is associated with altered expression of the skeletal muscle sarcoplasmic reticulum $\mathrm{Ca}^{2+}$-ATPase (SERCA). Methods-SERCA protein and mRNA were examined in the soleus muscles of eight female rats with heart failure induced by coronary artery ligation, six weeks after the procedure (mean (SEM) left ventricular end diastolic pressure 20.4 (2.2) $\mathrm{mm} \mathrm{Hg}$ ) and in six sham operated controls by western and northern analyses, respectively.

Results-SERCA-2a isoform protein was reduced by $16 \%$ (112 000 (4000) $v 134000$ (2000) arbitrary units, $p<0.001$ ), and SERCA-2a messenger RNA was reduced by $59 \%(0.24(0.06) v 0.58(0.02)$ arbitrary units, $p<0.001)$. Although rats with heart failure had smaller muscles $(0.54 \mathrm{mg} / \mathrm{g} v$ $0.66 \mathrm{mg} / \mathrm{g}$ body weight), no difference in locomotor activity was observed.

Conclusions-These results may explain the previously documented abnormalities in calcium handling in skeletal muscle from animals with the same model of congestive heart failure, and could be responsible for the accelerated muscle fatigue characteristic of patients with heart failure.

(Heart 1999;81:303-307)
\end{abstract}

Keywords: skeletal muscle; gene expression; heart failure; calcium-ATPase

Department of Medicine, University of California, San Francisco, California, USA

C S Long

B M Massie

Cardiovascular Research Institute, University of California, San Francisco K Chang

A Simonini

P Yue

Correspondence to: Dr Barry M Massie, Cardiology Section (111C), Veterans Affairs Medical Center, 4150 Clement Street, San Francisco, CA 94121, USA.

Accepted for publication 24 September 1998 with heart failure induced by coronary artery ligation, skeletal muscle fibres showed accelerated fatigue during electrical stimulation, associated with abnormal calcium transients char- acterised by a reduced amplitude and delayed rise and decline. ${ }^{16}$

As reviewed by Arai et al, ${ }^{17}$ similar abnormalities in calcium handling have been observed in cardiac muscle and have been associated with reduced expression of the sarcoplasmic reticulum $\mathrm{Ca}^{2+}$-ATPase (SERCA), which is responsible for calcium reuptake following contraction but also indirectly determines the amount of calcium availability for force development in both cardiac and skeletal muscle. Since we have recently observed that there are alterations in contractile protein and oxidative enzyme expression in skeletal muscle in rats with heart failure, ${ }^{18}$ we hypothesised that SERCA expression might also be downregulated, thus providing a possible mechanism for the changes in muscle function. This study was therefore undertaken to determine whether heart failure in rats is associated with altered expression of the skeletal muscle SERCA.

\section{Methods}

EXPERIMENTAL MODEL

The rat coronary ligation model was employed to induce heart failure, ${ }^{19}$ using previously described procedures. ${ }^{18}$ After acclimatisation for one week in the animal facility, female Sprague-Dawley rats weighing 240-260 g were anaesthetised with $2 \%$ isofluorane, intubated, and maintained on a Harvard rodent ventilator. A left thoracotomy was performed at the fifth intercostal space and, while the heart was exteriorised, the main left coronary artery was ligated 1-2 $\mathrm{mm}$ from its origin with a 7-0 suture (infarct group). In the controls, the same procedure was employed but the suture was not tied. The heart was then repositioned, and the muscle and skin layer closed with a purse string suture. In the infarct group, operative mortality was $30 \%$ and overall survival at the time of study six weeks postsurgery was $50 \%$. All sham operated rats survived. Postoperatively, rats were housed in twoanimal acrylic cages and received food and water ad libitum.

HAEMODYNAMIC MEASUREMENTS

At the time of study, rats were lightly anaesthetised with ketamine $(70 \mathrm{mg} / \mathrm{kg})$ plus xylazine $(10 \mathrm{mg} / \mathrm{kg})$, and the right carotid artery was cannulated with a $2 \mathrm{~F}$ micromanometer tipped catheter (Millar Instruments, Houston, Texas, USA). Under continuous pressure monitoring, the catheter was advanced retrogradely into the left ventricle and pressures were recorded. Only animals with left ventricular end diastolic 
Table 1 Haemodynamic and weight data

\begin{tabular}{llll}
\hline & Heart failure $(n=8)$ & Control $(n=6)$ & p Value \\
\hline LVEDP $(\mathrm{mm} \mathrm{Hg})$ & $20.4(2.4)$ & $5.2(0.5)$ & $<0.001$ \\
$\mathrm{dP} / \mathrm{dT}(\mathrm{mm} \mathrm{Hg} / \mathrm{s})$ & $7211(492)$ & $11333(551)$ & $<0.001$ \\
Soleus weight $(\mathrm{mg})$ & $156(5)$ & $178(3)$ & 0.006 \\
Soleus/body weight $(\mathrm{mg} / \mathrm{g})$ & $0.55(0.02)$ & $0.66(0.01)$ & $<0.001$ \\
\hline
\end{tabular}

Values are mean (SEM).

LVEDP, left ventricular end diastolic pressure.

pressures of more than $15 \mathrm{~mm} \mathrm{Hg}$ were included in the heart failure group $(n=8)$. Infarcted animals with lower left ventricular end diastolic pressures were not used in this study.

\section{ACTIVITY MONITORING}

Locomotor activity of matched heart failure and sham control animals was measured eight weeks after surgery by photocell monitoring, using our previously described techniques. ${ }^{18} 20$ In brief, animals were placed into an open field environment (Opto-Varimex Minor, Columbus Instruments, Columbus, Ohio, USA) measuring $16.5 \times 16.5$ inches $(42 \times 42 \mathrm{~cm})$, equipped with 15 photocell beams in each direction located $4 \mathrm{~cm}$ off the cage floor. Interruptions of photocell beams were cumulatively computer registered in 10 minute intervals over a 12 hour overnight period, one to three days before the animals were killed.

MUSCLE HARVESTING

With animals still anaesthetised, the hind limbs were dissected and the left soleus muscle was excised and quickly frozen in precooled isopentane before storage in liquid nitrogen for subsequent protein analysis. The contralateral muscles were then excised, snap frozen in liquid nitrogen, and stored for RNA analysis.

IMMUNODETECTION OF SERCA USING SOLEUS MUSCLE HOMOGENATES

Frozen soleus muscles were thawed and homogenised with $4 \times$ volume of phosphate buffer containing protease inhibitors
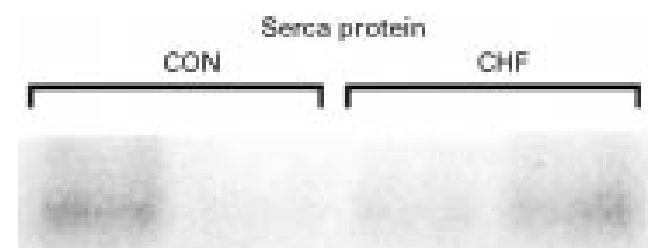

Figure 1 Immunoblot for SERCA-2a protein, showing two sham operated controls (CON) on the left and two heart failure rats $(\mathrm{CHF})$ on the right. (ethylenediaminetetra-acetic acid (EDTA) 2 $\mathrm{mM}$, leupeptin $2 \mu \mathrm{g} / \mathrm{ml}$, aprotinin $2 \mu \mathrm{g} / \mathrm{ml}$, and phenylmethanesulphonyl fluoride (PMSF) 0.5 $\mathrm{mM})$. Protein concentration of the muscle homogenates was determined by Bradford protein assay. ${ }^{21}$ Samples were incubated at room temperature for 30 minutes in $2 \times$ Laemmli buffer (Sigma, St Louis, Illinois, USA) and separated using a $10 \%$ sodium dodecyl sulphate (SDS) polyacrylamide gel electrophoresis. Each lane was loaded with $2 \mu \mathrm{g}$ protein. The electrophoresis buffer consisted of $50 \mathrm{mM}$ Tris, $150 \mathrm{mM}$ glycine, and $0.1 \%$ SDS. Separating gel was prepared with $10 \%$ (wt/vol) acrylamide, and $0.1 \%$ (wt/vol) N,N-Omethylene-bis-acrylamide in $100 \mathrm{mM}$ Tris, $300 \mathrm{mM}$ glycine, and $0.1 \%$ SDS.

After electrophoresis, proteins were transferred to a polyvinylidene difluoride (PVDF) membrane. The gels were stained when the transfer was completed using Coomassie blue to evaluate transfer efficiency. Membranes were incubated at $4^{\circ} \mathrm{C}$ overnight in blocking buffer (TBS; pH 7.5) which contained $20 \mathrm{mM}$ Tris/Cl, $0.9 \% \mathrm{NaCl}$, and was supplemented with $5 \%$ bovine albumin (fraction V, Sigma). Membrane was then incubated at room temperature for two hours with primary antibody, a polyclonal antibody (1/1000) against rabbit sarcoplasmic reticulum $\mathrm{Ca}^{2+}$ ATPase-2a isoform, ${ }^{22}$ which was kindly provided by Dr J Lytton. After washing with TBS containing $0.1 \%$ Tween, the membrane was incubated with ${ }^{125} \mathrm{I}$ labelled secondary antibodies for one hour at room temperature. The protein bands bound to the antibodies were visualized using autoradiography by exposing $x$ ray film (Kodak XOMAT) to the ${ }^{125} \mathrm{I}$ labelled membrane overnight at $-80^{\circ} \mathrm{C}$. The density of the autoradiograph was quantified using a scanning densitometer.

NORTHERN BLOT ANALYSIS

Total cellular RNA was isolated by the method of Chomczynski and Sacchi. ${ }^{23}$ RNA was quantified by absorbance at $260 \mathrm{~nm}$ and its integrity was determined by examining the $28 \mathrm{~S}$ and $18 \mathrm{~S}$ rRNA bands in ethidium bromide stained agarose gels. Total RNA (15 $\mu \mathrm{g} /$ lane) was separated by denaturing agarose gel electrophoresis, subjected to alkali pretreatment, transferred to nylon membranes, and cross linked by ultraviolet irradiation. $\beta$ Myosin heavy chain ( $\beta$-MHC) mRNA was detected by hybridisation to a 40 base oligodeoxyribonucleotide probe (Oncogene Science Inc, Uniondale, New York, USA) complementary to a unique 3' untranslated region of rat $\beta-\mathrm{MHC}$ mRNA. SERCA2 mRNA was detected by hybridisation to a fragment of the cDNA encoding rat SERCA-2a (courtesy of Dr W Dillmann, University of California, San Diego). ${ }^{24}$ This $2 \mathrm{a}$ isoform is found in both rat myocardium and slow twitch skeletal muscle fibre types. To provide an internal standard, all blots were hybridised with a riboprobe complementary to $18 \mathrm{~S}$ ribosomal RNA (Ambion Inc, La Jolla, California, USA). The cDNA and 18S RNA probes were prepared and radiolabelled by random primed labelling and T7 RNA 


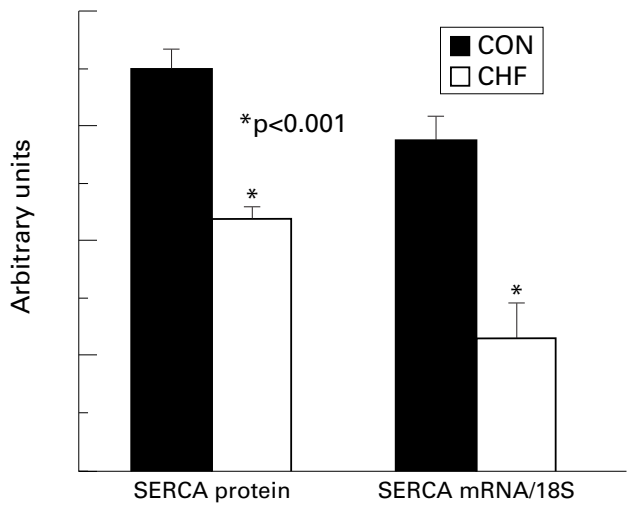

Figure 2 Mean values for the SERCA protein and $m R N A$ in arbitrary units. Both were significantly reduced in the heart failure rats. CON, control; $C H F$, chronic heart failure.

polymerase, respectively, and hybridised as previously described. All blots were exposed to Hyperfilm (Amersham, Uniondale, New York, USA) at $-80^{\circ} \mathrm{C}$. Exposure time was determined by preliminary experiments so as to provide quantitation of densitometric signals within the linear range of detection. For comparison, each blot contained RNA from both heart failure and control animals. Ribosomal (18S) RNA signals were unchanged relative to controls in the heart failure group. SERCA2 mRNA was quantified by scanning densitometry and software (Scan Analysis, Ofoto, Berkeley, California, USA) which used background subtraction and $18 \mathrm{~S}$ signals for normalisation and quantitation.

\section{STATISTICAL ANALYSIS}

The significance of intergroup differences in quantitative mRNA and protein variables was examined by Student's $t$ tests. Data are presented as means (SEM).

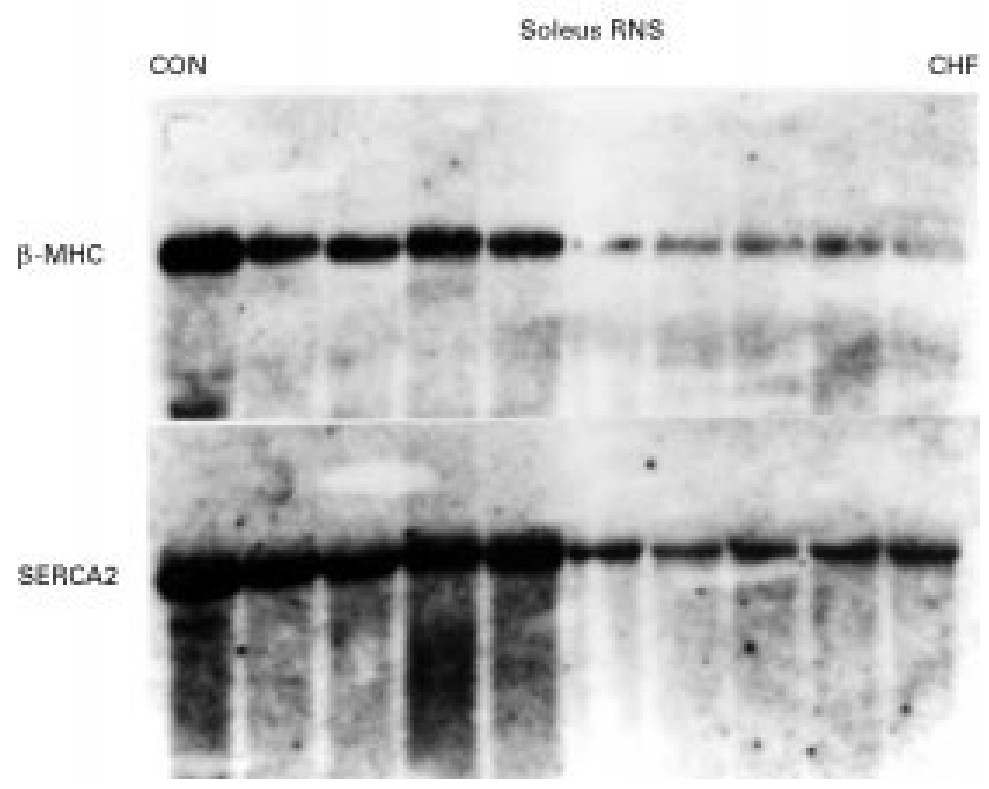

Figure 3 Northern blot showing reduced $\beta-M H C$ and SERCA $m R N A$ signals in the chronic heart failure (CHF) animals compared with controls (CON).

\section{Results}

HAEMODYNAMIC AND ACTIVITY MEASUREMENTS

Haemodynamic and weight data are shown in table 1. The heart failure group consisted of eight rats with myocardial infarctions and left ventricular end diastolic pressures $\geqslant 15 \mathrm{~mm}$ $\mathrm{Hg}$ (mean 20.4 (2.4) $\mathrm{mm} \mathrm{Hg}$ ). The control group consisted of six animals, all of which had a left ventricular end diastolic pressure of $\leqslant 8$ $\mathrm{mm} \mathrm{Hg}$ (mean $5.2(0.5)$ ). In addition to raised left ventricular end diastolic pressures, the heart failure group had a $40 \%$ reduction in maximum $\mathrm{dP} / \mathrm{dt}$ compared with the control group (7211 (492) v 11333 (551) mm Hg/s, $\mathrm{p}<0.001)$. The lower soleus muscle weight in the heart failure rats (156.0 (5.0) $\mathrm{mg} v 178.5$ (3.4) $\mathrm{mg}$ ), even after correction for body mass (0.55 (0.02) v $0.66(0.01) \mathrm{mg} / \mathrm{g}, \mathrm{p}<0.001)$, is consistent with skeletal muscle atrophy in the heart failure group. Overnight activity was not different between the heart failure rats and controls (3810 (360) v 3885 (240) counts/h).

SOLEUS PROTEIN AND RNA ANALYSIS

Figures 1 and 2 shows the result of soleus SERCA2 protein assays. The soleus muscles from the heart failure rats contained $16 \%$ less SERCA2 protein than those from the controls, as determined by densitometry (mean 112000 (4000) v 134000 (2000) arbitrary units, $\mathrm{p}<0.001)$. This reduction persisted when soleus SERCA2 protein content was normalised to that of myosin heavy chain, as determined by SDS-PAGE (2.57 (0.04) v 2.79 (0.02) arbitrary units, $\mathrm{p}<0.001)$.

The results of northern blots are shown in fig 3. Heart failure was associated with a greater than $50 \%$ decrease in SERCA2 mRNA in the soleus muscles $(0.24(0.06) v 0.58(0.02)$ arbitrary units for the shams, $\mathrm{p}<0.001)$ when standardised to the content of $18 \mathrm{~S}$ RNA per lane. The content of soleus mRNA encoding $\beta-\mathrm{MHC}$ in heart failure rates was also significantly reduced when compared with that in sham rats. There were disproportionate reductions in SERCA2 mRNA (> 50\%) and protein expression (16\%) in skeletal muscle during heart failure.

\section{Discussion}

In this study, a well established experimental model of congestive heart failure was used to demonstrate that chronic left ventricular dysfunction in rats is associated with alterations in the level of expression of specific RNA transcripts encoding the sarcoplasmic reticulum ATPase, as well as its cognate protein. The observed reduction in calcium transport gene expression corresponded with a decrease in mRNA encoding for $\beta$-MHC, the predominant contractile protein in the soleus, similar to our observations in a previous study. ${ }^{18}$ This new finding not only extends our previous findings of reduced expression of contractile proteins and oxidative enzymes in skeletal muscle, but also provides additional insight into the mechanisms contributing to skeletal muscle dysfunction in clinical heart failure. As noted in our previous study, the comparable activity levels of 
heart failure and control rats makes deconditioning an unlikely explanation for the muscle changes.

The present results add to the list of known derangements in skeletal muscle that may contribute to exercise intolerance in congestive heart failure. ${ }^{2-4}$ Several previous studies have shown that heart failure is associated with muscle atrophy at both the organ and fibre level. ${ }^{5-9}$ In addition, there is a shift in muscle fibre type distribution from slow twitch type I ( $\beta$-MHC) fibres to fast twitch type II fibres, and within the type II subgroup, from the more oxidative IIa fibres to the more glycolytic IIab and IIb phenotypes. ${ }^{7-9}$ These changes occur with a concomitant reduction in muscle oxidative enzyme activity across all fibre types..$^{7-9} 12$

Although these previously reported abnormalities may lead to accelerated acidosis and cause easy fatiguability with exercise, the degree of these changes is not as prominent as the pattern of fatigue, which appears to be disproportionately severe and rapid. For instance, in three studies conducted in men with congestive heart failure, we found that during 30 seconds of repetitive knee extensions force decreased by $40 \%$ to $50 \% .^{6914}$ In contrast, muscle strength was relatively preserved, muscle size was reduced by only $15 \%$, and there was a $20 \%$ reduction in the proportion of type I fibres. This discrepancy suggests that other factors may also contribute to muscle fatigue in heart failure.

In addition to alterations in myosin heavy chain gene expression shown in this and previous investigations, a possible mechanism contributing to the muscle fatigue of heart failure is altered intracellular calcium handling. Since calcium plays a vital role in muscle contraction, relaxation, and fatigue, reduced calcium availability could contribute to the observed functional abnormalities ${ }^{25}$ and at least partially explain the discordance between changes in strength and fatigue with exercise in heart failure patients. Indeed, Perreault et al previously reported a decline in amplitude and a prolongation of duration of the cytosolic calcium transient, with a more rapid decline in the calcium signal during repetitive twitch or tetanic stimulation in the extensor digitorum muscles from rats with postinfarction heart failure. ${ }^{16}$ As might be expected because of the critical role of calcium in excitation-contraction coupling, these changes were associated with diminished force development and a more rapid decline in force during stimulation. Taken together, these findings suggest that a defect in calcium transport or transport proteins may also contribute to impaired muscle performance and fatigue in heart failure. Of these, SERCA2 - which actively transports $\mathrm{Ca}^{2+}$ into the sarcoplasmic reticulum - has previously been investigated at the molecular level with regard to its function and regulation in the normal and failing heart. ${ }^{17}{ }^{26} 27$ This study is the first to report that gene expression of the slow/cardiac isoform of SERCA2 is downregulated in slow twitch soleus muscles in rats with heart failure. The dual findings of a reduction in both the
SERCA2 mRNA and protein indicate that this abnormality is regulated at the pretranslational level.

Our study further supports the hypothesis that heart failure induces intrinsic changes in skeletal muscle structure, function, and gene expression. ${ }^{918}$ The aetiology of the changes observed in heart failure is still not clear. These changes appear to be unrelated to the degree of locomotor activity or disuse. ${ }^{18}$ The calcium abnormalities also appear to be independent of fibre atrophy. ${ }^{16}$ Taken together, these findings suggest that heart failure may induce a specific myopathy in the periphery in which there is an alteration in expression of muscle proteins necessary for contractile and metabolic function.

\section{LIMITATIONS}

Our study has several limitations. First, we did not measure muscle function in these animals. However, both force development and relaxation were shown to be abnormal in the previously cited study by Perreault et al, using the same model of heart failure. ${ }^{16}$ A second limitation is the lack of corresponding measurements of sarcoplasmic reticular function in the soleus muscles. Again, the disturbances of calcium transients observed by Perreault et al during muscle stimulation in rats with heart failure are consistent with abnormalities of calcium handling proteins. ${ }^{16}$ Also, we did not examine the expression of other calcium handling proteins that may play a role in SERCA regulation and function, nor did we examine muscles other than the soleus, although abnormalities in this almost exclusively slow twitch muscle would be expected to play a particularly important role in early fatigue.

\section{CONCLUSION}

We have shown that heart failure in the rat is associated with a decrease in the expression of SERCA2 in skeletal muscle at both mRNA and protein level. This extends our previous observation of altered contractile protein and oxidative enzyme expression in this setting, and could explain both previous observations of abnormal skeletal muscle calcium handling in the rat and accelerated muscle fatigue in both human and experimental congestive heart failure. The similarity of many of the abnormalities in skeletal muscle to those observed in the failing heart is noteworthy. Further research into the signals for altered gene expression in skeletal muscle may not only help explain the mechanisms of exercise intolerance but also provide insight into the pathophysiology of myocardial dysfunction in heart failure.

This work was supported in part by grants 5T32-GM07456 (AS) and PO1-HL25847 (CSL) from the National Heart, Lung and Blood Institute, Bethesda, Maryland; the Department of Veterans Affairs Research Service, Washington, DC (CSL, BMM); and grants 92-41 (AS) and 96-79 (PY) from the California Affiliate of the American Heart Association, Burlingame, California.

1 Mason DT, Zelis R, Longhurst J, et al. Cardiocirculatory responses to muscular exercise in congestive heart failure. responses to muscular exercise in conge

2 Minotti JR, Christoph I, Massie BM. Skeletal muscle function, morphology, and metabolism in patients with congestive heart failure. Chest 1992;101(suppl):333-9S. 
3 Wilson JR, Mancini DM. Factors contributing to the exercise limitation of heart failure. 7 Am Coll Cardiol 1993; 22(suppl A): $93-8 \mathrm{~A}$.

4 Sullivan MJ, Hawthorne MH. Exercise intolerance in patients with chronic heart failure. Prog Cardiovasc Dis 1995;38:1-23.

5 Mancini DM, Walter G, Reichek $\mathrm{N}$, et al. Contribution of skeletal muscle atrophy to exercise intolerance and altered muscle metabolism in heart failure. Circulation 1992;85: 1364-73.

6 Minotti JR, Pillay P, Oka R, et al. Skeletal muscle size: relationship to muscle function in heart failure. $\mathcal{F}$ Appl Physiol 1993;75:373-81.

7 Mancini DM, Coyle E, Coggan A, et al. Contribution of intrinsic skeletal muscle changes to $31 \mathrm{P}-\mathrm{NMR}$ skeletal muscle abnormalities in patients with chronic heart failure. Circulation 1989;80:1338-46.

8 Sullivan MJ, Green HJ, Cobb FR. Skeletal muscle biochemistry and histology in ambulatory patients with chronic istry and histology in ambulatory patien.

9 Massie BM, Simonini A, Sahgal P, et al. Relationship of systemic and local muscle exercise capacity to skeletal muscle temic and local muscle exercise capacity to skeletal muscle characteristics in patients with

10 Wilson JR, Fink L, Maris J, et al. Evaluation of energy metabolism in skeletal muscle of patients with heart failure with gated phosphorus-31 nuclear magnetic resonance. Circulation 1985;71:57-62

11 Massie BM, Conway M, Yonge R, et al. Skeletal muscle metabolism in patients with congestive heart failure: relation to clinical severity and blood flow. Circulation 1987;76:1009-19.

12 Drexler H, Reide U, Just $\mathrm{H}$. Alterations of skeletal muscle in chronic heart failure. Circulation 1992;85:1751-9.

13 Buller NP, Jones DA, Poole-Wilson PA. Direct measurement of skeletal muscle fatigue in patients with chronic heart failure. Br Heart f 1991;65:20-4.

14 Minotti JR, Christoph I, Oka R, et al. Impaired skeletal muscle function in patients with congestive heart failure:
relationship to systemic exercise performance. 7 Clin Invest 1991;88:2077-82.

15 Minotti JR, Pillay P, Chang L, et al. Neurophysiological assessment of in patients with congestive heart failure. Circulation 1992;86:903-8.
16 Perreault CL, Gonzalez-Serratos H, Litwin SE, et al. Alterations in contractility and intracellular $\mathrm{Ca}^{2+}$ transients in solated bundles of skeletal muscle fibers from rats with chronic congestive heart failure. Circ Res 1993;73:405-12.

17 Arai M, Matsui H, Periasamy M. Sarcoplasmic reticulum gene expression in cardiac hypertrophy and heart failure. Circ Res 1994;74:555-64.

18 Simonini A, Long CS, Dudley GA, et al. Heart failure in rats causes changes in skeletal muscle morphology and gene expression that are not explained by reduced activity. Circ Res 1996;79:128-36.

19 Pfeffer MA, Pfeffer JM, Fishbein MC, et al. Myocardial infarct size and ventricular function in rats. Circ Res 1979;44: arct size

20 Tyler TD, Tessel RE. A new device for the simultaneous measurement of locomotor and stereotypic frequency in mice. Psychopharmacology 1979;64:285-90.

21 Bradford MM. A rapid and sensitive method for the quantitation of microgram quantities of protein utilizing the principle of protein-dye binding. Anal Biochem 1976;72:24854.

22 Lytton J, Westlin M, Burk SE, et al. Functional comparisons between isoforms of the sarcoplasmic or endoplasmic reticulum family of calcium pumps. F Biol Chem 1992;267: 14483-9.

23 Chomczynski P, Sacchi N. Single-step method of RNA isolation by acid guanidinium thiocyanate-phenol-chloroform extraction. Anal Biochem 1987;162:156-9.

24 Rohrer DK, Hartong R, Dillmann WH. Influence of thyroid hormone on slow sarcoplasmic reticulum $\mathrm{Ca}^{2+} \mathrm{ATPase}$ and MHC a gene expression in cardiac myocytes. $\mathcal{F}$ Biol Chem 1991;266:8638-46.

25 Williams JH, Klug GA. Calcium exchange hypothesis of skeletal muscle fatigue: a brief review. Muscle Nerve 1995;18:421-34.

26 Mercadier JJ, Lompré AM, Duc P, et al. Altered sarcoplasmic reticulum $\mathrm{Ca}^{2+}$ ATPase gene expression in the human ventricle during end-stage heart failure. $\mathcal{F}$ Clin Invest 1990; 85:305-9.

27 de La Bastie D, Levitsky D, Rappaport L, et al. Function of the sarcoplasmic reticulum and expression of its $\mathrm{Ca}^{2+}$ ATPase gene in pressure overload induced cardiac hypertrophy in the rat. Circ Res 1990;66:554-64. 